This policy paper was originally developed and circulated in 2014. Aspects of it are now outdated, others aren't. The paper is uploaded on SocArxiv in 2019 to contribute to a growing debate on outcome funding structures.

\title{
A Clearinghouse for Outcome Funds
}

Richard Sedlmayr

Despite persistent and widespread enthusiasm, pay-for-success has been slow to materialize - especially in international development assistance. This concept note:

- argues that the availability of credible outcome funding is the most important bottleneck to the development of the sector;

- hypothesizes that once credible outcome funding is made available, markets should be able to solve most other coordination challenges, including input financing; and

- proposes a testable solution: a 'clearinghouse' that settles outcome-based contracts between funders and the rest of the social sector.

\section{What Is Pay-For-Success?}

Over the course of the last decade, there has been increasing interest in funding arrangements that withhold funding from providers until outcomes materialize; in other words, that pay for success. These include Advance Market Commitments (guarantees to purchase not-yet-developed technologies once they are developed); Social / Development Impact Bonds (which involve private investors in the financing of nonprofit activities); and Cash-On-Delivery Aid (outcome-based aid agreements between foreign aid donors and recipient governments).

In all of these cases, the institution that ultimately pays for the outcomes is typically referred to as the outcome funder. But simply paying for outcomes is not enough: the outcome funder must also credibly commit to doing so ex ante; manage funds in the interim; and have a plan B in case outcomes do not materialize. Also, it must be willing to refrain from activities funders usually engage in (e.g., programmatic due diligence) and acquire new competencies (e.g., contracting). The gist of this paper is that funders are not typically set up to do this, nor under much pressure to change.

\section{Why Is Pay-For-Success A Good Idea?}

Paying for outcomes may have several advantages over paying for inputs:

- Moral hazard. The costs of misappropriation, negligence, and other hidden actions accrue to the providers themselves, not to funders. Providers are in a better position to prevent these problems than funders are.

- Flexibility. Because moral hazard is less of an issue, funders no longer need to impose potentially stifling restrictions on the use of funds, which in turn gives more flexibility (and potentially an incentive) to providers to engage in iterative adaptive learning.

- Adverse selection: Under input funding, money talks, and providers have an incentive to design or bid on projects that follow donor narratives, as opposed to projects that they consider most suitable for their context. Meanwhile, under pay-for-success, providers who do not believe that they can 
cost-effectively deliver the desired outcomes have no incentive to even try to enter an agreement in the first place.

- Pricing: Outcome funding agreements negotiate the price of outcomes, not the costs of inputs. These prices reflect the risk of failure: risky projects (i.e., ones where the outcomes are perceived as uncertain) will cost funders more. This is essential for the efficient allocation of funds.

Furthermore, if they are made public, they can generate valuable knowledge on the risk-benefit profiles of different projects across the social and development sector.

- Feedback loops: The link between provider performance and financial strength is enhanced; highperforming organizations automatically receive more funding.

\section{When And Where Is Pay-For-Success Viable?}

At least four factors determine the viability of outcome funding in a given situation:

Outcomes. Not all donor objectives are suitable for outcome funding. The specified outcomes must likely be:

- Clearly defined and unambiguously measurable

- Clearly attributable to specific activities

- Tied to goals that providers have agency over

- Achievable not too far in the future

- Incentive-compatible. In some contexts, outcome targets could yield perverse results. For instance, providers may:

- Lose intrinsic motivation that might otherwise be an important driver of their performance.

- Prioritize activities that are remunerated while discontinuing valuable peripheral activities.

- Try to 'game' the system by improving outcome indicators without improving actual outcomes

Knowledge. It makes sense to distinguish two forms of knowledge:

- 'Fundamental' knowledge is the evidence base for the type of intervention that is being proposed. Unless both the donor and provider share some empirical basis, it may be difficult for them to finalize an outcome funding agreement: the donor may be concerned about overpaying for results that might be easy to achieve, while the provider may be concerned about embarking on an impossible task.

- 'Local' knowledge does not deal with the fundamental mechanisms of an intervention, but the specifics of how it is implemented. This knowledge tends to be asymmetric: providers have more information about their own suitability and performance, and usually the context as well, than do donors. Such information asymmetries are a central justification for engaging in outcome funding, as discussed above.

Institutions. Even where a pay-for-success arrangement makes sense in principle, institutional barriers could make it exceedingly difficult.

- Providers can face a large variety of impediments, but one recurring challenge is that they need to at least partially finance projects up-front. This means that they not only need access to liquidity, but also need to be able to cover the risk that outcomes are not achieved and the donor does not pay. Many providers are not in a position to do this independently.

- Investors / capital markets could help overcome this challenge in principle, but may lack an adequate basis for appraising the risks of social projects.

- Donors face several possible barriers to outcome funding, including: 
- Cash flow challenges: Outcome funding can introduce uncertainty about the timing and scale of payouts, yet many funders are required to disburse on a specific schedule - often for legal reasons.

- Bureaucratic challenges: Outcome funding would require changes to the decision-making processes of all parties involved. Funders may need to fundamentally revisit internal procedures, but organizational inertia may inhibit this.

- Capacity challenges: Some required skills may be in short supply. For instance, funders may not know how to structure outcome agreements that are cost-effective, attractive to providers, and do not create an opportunity to 'game' the system.

- Identity challenges: Outcome funding could be perceived as changing the identity of donors from that of the powerful decision-maker to that of the organization that picks up the tab.

- Beliefs and attitudes about the benefits of outcome funding can also be a barrier. For instance, a donor may be overconfident and ignore information asymmetries, or may not believe that pay-forsuccess can overcome aid failures. Providers may be concerned that a failure to deliver the agreedupon outcomes will tar its reputation. Both could also have aesthetic or ethical concerns about 'monetizing' social outcomes.

\section{Transaction costs.}

- Pay-for-success contracts tend to integrate more parties than input-funded projects, and do so in a more complex manner.

- Contracting becomes more sophisticated.

- High quality evaluation is no longer a luxury; it becomes a necessity.

- Risks are transferred away from funders and towards other players (such as providers and/or investors); however, funders tend to be less risk-averse than other sector players, so financing costs will tend to rise.

Depending on the context, these costs may make outcome funding quite expensive.

\section{Why Isn't Pay-for-Success More Common?}

In terms of the outcome and knowledge criteria, it would appear that broad swaths of international development assistance should be suitable for, and could benefit from, pay-for-success. So why isn't pay-for-success more common? The framework above suggests that it likely has something to do with institutions and transaction costs.

As discussed, one barrier is the financing challenge: somebody needs to fund project activities in the first place, and providers are often in a weak position to do this themselves. Social / Development Impact Bonds address this by integrating risk capital into the equation. This solution creates the full feedback loop: an outcome funder commits to making an outcome payment, contingent on results; investors finance service providers to deliver services; and independent evaluators report back to the outcome funder, who pays the investor if the results indicate success. 

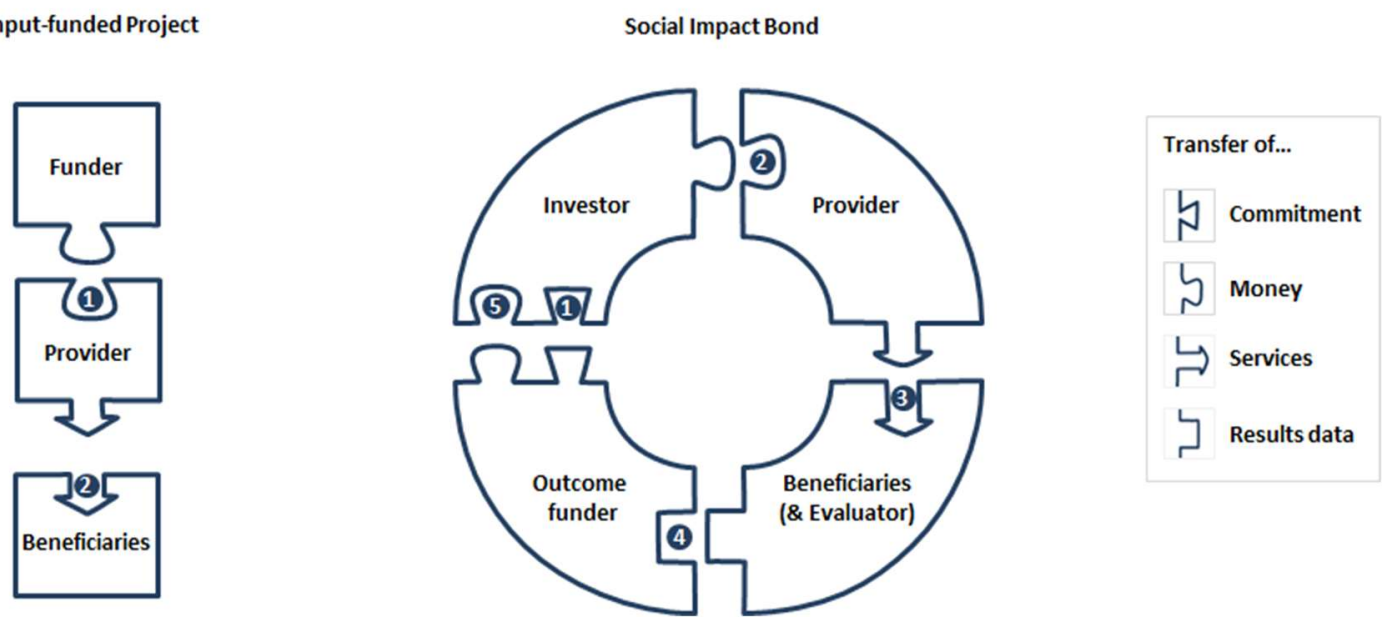

But despite their widespread promotion, few social impact bonds have materialized, and development impact bonds have not even passed the pilot stage.

One might suspect that this has something to do with the availability of investors: after all, they are the only fundamentally 'new' player in the figure above, and as discussed, they may not be skilled at appraising the risks of social projects. However, this is implausible. Investors (including nonprofit investors) are driven by market forces and allocate capital based on risk-return profiles. Attracting investors, then, should be mostly a matter of attractive commitments. Attractive commitments not only promise a risk premium; most importantly, they should be credible and give certainty that (contingent on results) payments will be made.

After working two years on their origination, the nonprofit pay-for-success advisor Instiglio concluded that financing is not necessarily the key constraint to the development of pay-for-success; funders are. This may seem puzzling: in the abstract, outcome funding would seem attractive for funders, as the burden of ensuring that results actually materialize, and the risk that they don't, is shouldered by others. But the framework above helps explain this: funders face specific legal, bureaucratic, capacity, and identity barriers to becoming outcome funders; and unlike other players, they are not subject to market forces that compel them to change.

In other words, outcome funders need to have funds, and funders have funds, but that does not mean that funders can easily become outcome funders.

Funder

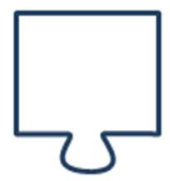

Outcome Funder

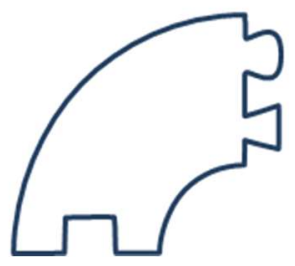

\section{The Clearinghouse Concept}


The above raises the question if there is a way to integrate funders into the process without downplaying their needs. Ideally, such a solution would solve funder's challenges as follows:

- Cash Flow Challenges: The solution would need to allow funders to predict payouts;

- Bureaucratic Challenges: The solution would not require funders to fundamentally re-invent internal processes;

- Capacity Challenges: The solution would need to fill any capacity gaps;

- Identity Challenges: The solution would need to leave essential decision-making powers of funders intact.

I suggest that this might be solved by a 'clearinghouse' that receives directions, priorities, and funds from private and public donors and translates these into separate, outcome-based commitments.

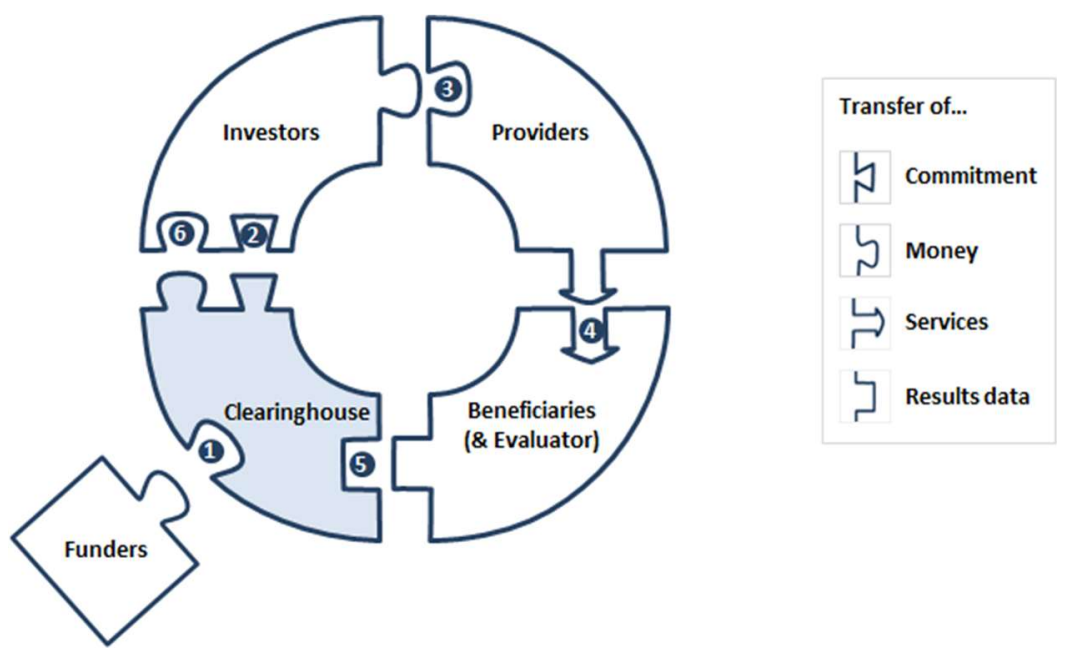

Wouldn't such an institution make things even more complicated, further raising transaction costs? I argue it would do the contrary. Past attempts to develop pay-for-success projects have predominantly involved 'matchmaking' attempts: project concepts were developed by pay-for-success specialists and 'shopped around' to providers, donors, and investors. I argue that this is the wrong approach to promote pay-for-success, for the reasons outlined above: funders different from outcome funders, and unlike providers and investors, they are not subject to market forces. I therefore propose to start with the funders, accept their priorities, and translate these into demand for outcomes. I predict that once credible commitments are in place, market forces should then lead the rest of the sector to fall into place, reducing the cost of originating pay-for-success projects. 